Running Head: ACTION WORDS AND THE MOTOR SYSTEM

\title{
Interwoven Functionality of the Brain's Action and Language Systems
}

\author{
Véronique Boulenger ${ }^{1}$ and Tatjana A. Nazir ${ }^{2}$ \\ ${ }^{1}$ Laboratoire Dynamique du Langage, UMR 5596 CNRS - Université Lyon 2, Lyon, France \\ ${ }^{2}$ Laboratoire sur le Langage, le Cerveau et la Cognition, UMR 5230 CNRS - Université \\ Lyon 1, Bron, France
}

Address for correspondence:

Dr Véronique Boulenger

Laboratoire Dynamique du Langage CNRS UMR 5596

14 avenue Berthelot

69363 Lyon Cedex 07 (FRANCE)

Tel : $+33(0) 4.72 .72 .79 .24$

Fax : $+33(0) 4.72 .72 .65 .90$

Veronique.Boulenger@ish-lyon.cnrs.fr 


\begin{abstract}
Theories of embodied cognition consider language understanding as intimately linked to sensory and motor processes. Here we review evidence from kinematic and electrophysiological studies that processing of words referring to bodily actions, even when subliminally presented, recruits the same motor regions that are involved in motor control. We further discuss the functional role of the motor system in action word retrieval in light of neuropsychological data showing modulation of masked priming effects for action verbs in Parkinson's patients as a function of dopaminergic treatment. Finally, a neuroimaging study revealing semantic somatotopy in the motor cortex during reading of idioms that include action words is presented. Altogether these findings provide strong arguments that semantic mechanisms are grounded in action-perception systems of the brain. They support the existence of common brain signatures to action words, even when embedded in idiomatic sentences, and motor action. They further suggest that motor schemata reflecting word meaning contribute to lexico-semantic retrieval of action words.
\end{abstract}

Keywords: action words, motor action, idioms, Parkinson's Disease, kinematics, EEG, fMRI 
Recent evidence has rapidly accumulated in favour of embodied theories of semantics suggesting that conceptual representations are grounded in action-perception systems of the brain (Barsalou, 2008; Fischer \& Zwaan, 2008; Gallese \& Lakoff, 2005; Pulvermüller, 2005; Pulvermüller \& Fadiga, 2010). In this view, the sensory-motor system characterizes the semantic content of concepts in terms of the way our body interacts with the world. "People's subjective, felt experiences of their bodies in action provide part of the fundamental grounding for language and thought" (Gibbs, 2003). In line with this view, brain imaging studies revealed that retrieving knowledge about objects activates a distributed circuit of property representations in and around the brain regions dedicated to perception and action. Making judgements about the colour of an object recruits cortical area V4 involved in the processing of colour sensations, whereas perceiving a tool activates premotor regions that are activated when actually using this tool (Martin, 2007; Martin \& Chao, 2001; Martin, Wiggs, Ungerleider, \& Haxby, 1996; see Ullman, 2007 for a review on the mental lexicon and its neural bases). Studies with patients also showed that lesions in modality-specific brain regions increase the probability of losing categories that are mainly characterized by the properties processed in these areas. Whereas damage to fronto-parietal areas has been associated with selective deficit in processing artefacts (Caramazza \& Hillis, 1991), impairment for processing natural kinds has been reported following lesions to inferior-temporal visual areas (Gainotti \& Silveri, 1996; Warrington \& Shallice, 1984). In the realm of language, a large range of empirical data also demonstrates that word meaning is inextricably shaped by embodied action and perception. Perception of words referring to tactile, gustatory or olfactory knowledge activates brain regions that underlie encoding of these same sensory experiences (Goldberg, Perfetti, \& Schneider, 2006; Simmons, Martin, \& Barsalou 2005). Similarly, words or sentences that denote bodily actions activate different parts of motor and premotor regions (Desai, Binder, Conant, \& Seidenberg, 2010; Hauk, Johnsrude, \& 
Pulvermüller, 2004; Tettamanti, Buccino, Saccuman, Gallese, Danna, Scifo, et al., 2005). Using functional Magnetic Resonance Imaging (fMRI), Hauk et al. (2004) demonstrated somatotopic overlap of activation in areas along the motor strip for reading words describing actions performed with arm (pick), leg (kick) or mouth (lick) and for physical actions using the same effectors. Similar results were obtained with action words embedded in sentences such as The man wrote the letter or The man kicked the ball (Tettamanti et al., 2005). Even reading about a sport such as hockey activates the motor cortex specifically in experts' brains (Holt \& Beilock, 2006). This language-induced motor activity has further been shown to emerge rapidly after word onset, within a few hundreds of milliseconds (Hauk \& Pulvermüller, 2004; Pulvermüller, Shtyrov, \& Ilmoniemi, 2005a; Shtyrov, Hauk, \& Pulvermüller, 2004) and to specifically affect word recognition (Pulvermüller, Hauk, Nikulin, \& Ilmoniemi, 2005b). Using Transcranial Magnetic Stimulation (TMS), which consists of applying magnetic pulses to potentiate (stimulate) or depress (inhibit) transiently cortical excitability (depending on stimulation frequency and intensity; see Pascual-Leone, Tormos, Keenan, Tarazona, Canete, \& Catala, 1998, and Walsh \& Cowey, 2000), Pulvermüller et al. (2005b) showed that subthreshold stimulation of the arm representation in the left hemisphere led to faster processing of arm-related words relative to leg-related words. When subthreshold TMS was applied to the leg area, the opposite pattern of faster leg-related than arm-related word responses emerged. Finally, behavioural studies have also evidenced strong connections between language comprehension and motor processes, as shown by the so-called "action compatibility effect" (Glenberg \& Kaschak, 2002; Scorolli \& Borghi, 2007; Tucker \& Ellis, 2004; Zwaan \& Taylor, 2006). For instance, reading sentences that describe movements towards or away from the body affects sensibility judgements that require manual responses congruent or not with the actions depicted by the sentences. 
Altogether these findings reveal tight functional links between systems for language and action and support a distributed interactive model of word semantics in the brain (Pulvermüller, 2005). Despite these highly appealing results, several questions remained however unsolved. First, showing that action word processing activates motor regions does not tell us whether these same structures also control motor behaviour or whether they are language-specific despite being located in the motor system. Second, has not been clear whether activity in motor regions reflects word processing per se or mental imagery of the actions depicted by the words that occurs after word identification. Motor activation during reading or hearing of action words could indeed result from "post-understanding translation" of the depicted actions into action patterns (Glenberg \& Kaschak, 2002). Such an interpretation would imply that activity in cortical motor regions can only be considered a byproduct of language processing without specific functional relevance. Third, the contribution of motor regions to action word processing still needs to be specified: are these regions crucial so that a "motor pathology" can selectively affect word recognition? Fourth and last, previous work did not address one of the most important predictions of embodied semantic models, namely that sensorimotor brain regions should come into play during abstract word processing as well. Here we review evidence from four studies directly addressing these questions and showing that:

(1) reading action verbs specifically interferes with concurrent movement execution, thus the same structures that control motor behaviour are recruited during language processing (Boulenger, Roy, Paulignan, Deprez, Jeannerod, \& Nazir, 2006; Nazir, Boulenger, Roy, Silber, Jeannerod, \& Paulignan, 2008).

(2) subliminal perception of action verbs hinders motor preparation, refuting the motor imagery interpretation (Boulenger, Silber, Roy, Paulignan, Jeannerod, \& Nazir, 2008a). 
(3) processing of action verbs is subtly impaired in Parkinson's patients, suggesting the implication of motor regions in (action) language understanding (Boulenger, Mechtouff, Thobois, Broussolle, Jeannerod, \& Nazir, 2008b).

(4) reading idiomatic sentences that include action words (She grasped the idea) activates the motor and premotor cortex somatotopically (Boulenger, Hauk, \& Pulvermüller, 2009).

Shared Cortical Substrates for Action Verb Processing and Motor Action

Although previous imaging and behavioural studies suggested that action word processing recruits the motor and premotor cortex (Glenberg \& Kaschak, 2002; Hauk et al., 2004; Zwaan \& Taylor, 2006), clear-cut evidence was crucially lacking as to whether action word processing and overt motor behaviour share common neural substrates so that cross-talk would emerge if the two were performed concurrently. To address this issue, we designed a novel paradigm that allowed analysis of the kinematics of a grasping movement performed in combination with a language task (Boulenger et al., 2006). We asked participants to make a lexical decision (i.e. decide whether a visually-presented letter string is a word or not) on action verbs, concrete nouns and pseudo-words. The originality of this design was that participants gave their response by performing a grasping movement towards an object placed in front of them. Verbs denoted actions performed either with the hand/arm (e.g., peindre/'paint'), leg (e.g., sauter/'jump') or mouth (e.g., mâcher/'chew'), whereas nouns referred to imageable concrete entities that cannot be manipulated (e.g., falaise/'cliff'). In a first experiment, on appearance of a signal on the screen, participants had to reach and grasp a small object placed in front of them. The onset of the movement triggered the presentation of a stimulus on the screen. If the stimulus was a word (verb or noun), participants had to carry on their movement, whereas if it was a pseudo-word they had to stop it and to move back to 
the home-pad. In a second experiment, the paradigm was similar except that stimuli were presented before the movement. Participants had to grasp the object if the stimulus was a word, while they had to lift their hand from the home-pad if it was a pseudo-word.

Movements were recorded using an Optotrak 3020 (Northern Digital) and visualized and analyzed using Optodisp software (INSERM CNRS UCBL; Thevenet, Paulignan, \& Prablanc, 2001). We measured two kinematic landmarks which reflect the motor commands of the brain, namely latency and amplitude of the wrist acceleration peak.

Results revealed that word category significantly affected movement kinematics in both experiments. In experiment 1 (i.e. simultaneous language and motor tasks), latency of the wrist acceleration peak was longer and peak amplitude was smaller when participants read action verbs than when they read concrete nouns (Figure 1). As wrist acceleration peak indexes initial muscular contractions, longer latency and reduced amplitude suggest that lexico-semantic access to action verbs hindered simultaneous execution of the grasping movement. In experiment 2 (i.e. language task before the movement), a reverse pattern of results was observed as latency of the acceleration peak was shorter when action verbs had been presented prior to movement execution compared to concrete nouns (Figure 1). This suggests that processing of action verbs primed subsequent motor performance. It is also worth mentioning that although the primary goal of this study was not to differentiate between subclasses of verbs, cross-talk tended to be stronger when verbs called the same effector as the one used to perform the movement (arm/hand) than when they depicted mouth or leg actions, suggesting that language-induced motor effects are somatotopic (Hauk et al., 2004).

Figure 1 
These findings therefore demonstrate that almost instantly after word/movement onset (within $180 \mathrm{~ms}$ ), reading action verbs can specifically interfere with or facilitate movement execution depending on the temporal sequence of the tasks. We interpreted this cross-talk as evidence for competition for common resources between (action) language and motor processes: when action verbs are processed simultaneously with movement execution, they hinder motor performance (Experiment 1), but when they are processed before movement onset, they prime the motor task (Experiment 2). Such results are particularly coherent with TMS studies showing that whereas TMS applied to the motor cortex during action word encoding slows down reaction times to these words (Buccino et al., 2005), magnetic stimulation after word onset leads to faster reaction times (Pulvermüller et al., 2005b; see also Rueschemeyer, Lindemann, van Rooij, van Dam, \& Bekkering, 2010 for related behavioural findings). The earliness of the language-induced motor effect in Experiment 1, namely in a time-window within which first lexico-semantic effects are typically observed (Hauk, Pulvermüller, Ford, Marslen-Wilson, \& Davis, 2009), further suggests that action word processing does engage cortical structures that are involved in motor programming and control. In other words, motor activation would not reflect a side-effect of word recognition but would result from rapid and automatic spreading of activation within a distributed neural network, reflecting initial access to word lexico-semantic representations (Hauk \& Pulvermüller, 2004; Pulvermüller, 2005). Action-related information would thus be "woven into the cortical neuron webs representing and processing words" (Hauk \& Pulvermüller, 2004). The specific interaction between action verbs and movement also agrees with previous works postulating that representations of verbs and nouns involve partly different cortical networks, with verbs, which are frequently associated with actions, specifically engaging frontal motor regions (Boulenger, Decoppet, Roy, Paulignan, \& Nazir, 2007; Caramazza \& Hillis, 1991; Damasio \& Tranel, 1993). Studies with brain-lesioned patients indeed show that 
while damage to left frontal motor areas correlates more often with deficits in processing action verbs, damage to left temporal regions is more often associated with difficulties for noun retrieval (Caramazza \& Hillis, 1991). We further showed that word age-of-acquisition (AoA) differentially affected recognition of action verbs and concrete nouns in a lexical decision task in healthy participants (Boulenger et al., 2007). AoA effects refer to the faster and more accurate processing of words that are acquired early in life than of later-acquired words and is thought to reflect the way information is stored and accessed in the brain (Carroll \& White, 1973; Ghyselinck, De Moor, \& Brysbaert, 2004; see Rastle, 2007 for a review on visual word recognition). In our study, we found that AoA influenced identification of concrete nouns but not of action verbs. However, this was only observed for verbs denoting actions belonging to the human motor repertoire whereas classical AoA effects were seen for verbs depicting actions performed by animals. We suggested that the age at which neural representations of action verbs establish may not only depend on learning-age of their verbal form but also on developing motor behaviour. The age at which our motor system is mature enough to learn to perform the actions denoted by verbs may indeed constrain the neural architecture of these words. This suggests the existence of intimate links between language and motor systems that would develop early in life and that would be of crucial importance for language acquisition and understanding.

Motor Activity Reflects Lexico-Semantic Processing of Action Verbs, not Motor Imagery

One major criticism for the involvement of motor regions in action word retrieval is that motor activity could result from mental imagery of the actions described by the words. By showing spreading of activity in motor/premotor cortex during action word processing (Pulvermüller et al., 2005a) and interference between action verb reading and motor 
performance (Boulenger et al., 2006; Nazir et al., 2008) very shortly after word onset, strong arguments against this interpretation have been provided. Nevertheless, this possibility cannot be fully discarded unless interference effects are observed while words are subliminally presented, as words that are not consciously perceived cannot trigger mental imagery. In a study combining EEG (ElectroEncephaloGraphy) and kinematics recordings (Boulenger et al., 2008a), we tackled this issue by investigating cross-talk between language and motor processes using words that were masked by other visual symbols and that were presented too fast to be consciously perceived. It is well-known from behavioural and imaging studies that although participants do not consciously perceive a visually masked word, the subliminal stimulus automatically preactivates essential parts of the neural network underlying word processing (Dehaene, Naccache, Cohen, Le Bihan, Mangin, Poline, et al., 1998, 2001; Diaz \& McCarthy, 2007; Kiefer, 2002) and facilitates later recognition of that same word or of a semantically related word (i.e. masked priming; Forster \& Davis, 1984; Greenwald, Draine, \& Abrams, 1996; Marcel, 1983). Our reasoning was that if motor regions come into play during action word processing, they should be activated even when words are masked. We examined the impact of subliminal displays of action verbs on the neurophysiological correlates of motor preparation (EEG) and on subsequent movement execution (kinematics). Participants were asked to prepare to perform a grasping movement towards an object on appearance of a warning signal (S1) on the screen. When a go-signal (S2) was presented, they had to reach and grasp the object as fast and accurately as possible. During the preparation period (i.e. time-interval between S1 and S2), a lower-case letter string (arm-related action verb or nonaction-related concrete noun) was subliminally presented for $50 \mathrm{~ms}$ (preceded and followed by 100 ms-long masks). Participants were told to pay attention to the entire sequence of rapidly changing visual display during movement preparation. A control task in which 12 participants different from the participants in the EEG study were presented with the same 
visual displays and were explicitly asked to identify as many word stimuli as possible suggested that our stimuli were indeed not consciously perceived (14\% of correct identification). As a neurophysiological marker of motor preparatory processes, we chose the Readiness Potential (RP; Kornhuber \& Deecke, 1965; Colebatch, 2007) which is a slow negative wave starting approximately $1 \mathrm{~s}$ prior to movement onset with maximum amplitude at centro-lateral recording sites and thought to arise from premotor and primary motor areas. Movement kinematics was recorded and analyzed using the same method as the one used in Boulenger et al. (2006).

Our results showed the emergence of a strong RP over the central region, indicating that participants correctly prepared to perform the movement. Crucially, results revealed that subliminal presentation of action verbs vs. concrete nouns reduced the slope of the RP: the RP was less negative in the verb than in the noun condition (Figure 2). Kinematic analyses confirmed this pattern of results as amplitude of the wrist acceleration peak was reduced following action verb compared to concrete noun displays. Hence, subliminally presenting action verbs during movement preparation had a stronger interfering effect on concurrent motor processes than presenting concrete nouns without motor associations.

Figure 2

These findings reveal that action verb processing interferes not only with actual motor performance but also with movement preparation. This agrees with the cross-talk between action verb reading and movement execution we previously observed on the wrist acceleration peak (Boulenger et al., 2006), which typically occurs in the first $200 \mathrm{~ms}$ of movement onset and strongly depends on motor preparation (Schmidt, Zelaznik, \&, Frank, 1979). The interference effect further emerged shortly after word onset (within 150-200 ms) 
and while words were not consciously perceived. This clearly suggests immediate access to sensory-motor knowledge during language comprehension and favours the view that language-induced perturbation of motor performance reflects the engagement of motor structures, such as the premotor and primary motor cortex, in action word processing as such and cannot be accounted for by post-lexical motor imagery processes. Such an assumption is in line with a recent fMRI study (Hauk et al., 2008) showing that activity in action-related brain regions during action word reading is modulated by word frequency, thus reflecting aspects of lexico-semantic processes (see also Gold, Balota, Jones, Powell, Smith, \& Andersen, 2006; Hauk \& Pulvermüller, 2004; Wheatley, Weisberg, Beauchamp, \& Martin, 2005 for related findings). Also consistent with this interpretation is the fact that masked subliminal priming is thought to reflect automatic access to lexico-semantic information about words (Posner \& Snyder, 1975; Neely, 1991), diminishing the possibility of using strategically-driven processes, such as deliberate mental imagery, to identify target stimuli. Neuroimaging studies have further revealed selective activation of cortical and sub-cortical areas that code for word-specific semantic dimensions during subliminal presentation of these words. For instance, increased activation of the amygdala, known to respond to threatening stimuli, was seen during subliminal display of fearful words (Naccache, Gaillard, Adam, Hasboun, Clemenceau, Baulac, et al., 2005), suggesting that subliminal primes can reach lexico-semantic levels of processing. We propose that in our study, subliminal displays of arm-related action verbs preactivated parts of their neural networks, including arm-related motor/premotor regions, and that preactivation of these regions during concurrent arm movement preparation penalized the motor task due to competition for shared resources. Although this does not directly apply to our study which did not use a proper masked priming procedure, the reader should however be aware that evidence for masked semantic priming is still inconsistent in the literature (Kiefer, 2002; Perea \& Gotor, 1997; Quinn \& Kinoshita, 
2008; for reviews, see for instance Bueno \& Frenck-Mestre, 2008 and Kouider \& Dehaene, 2007). It has particularly been suggested that masked semantic priming may result from “acquired mappings between targets and response keys that are also applied to subliminal presented primes" (Damian, 2001; see also Abrams \& Greenwald, 2000). This particularly holds for subliminal primes that have previously been used as supraliminal targets requiring a response. In our study, masked action words were not followed by any target and no overt task had to be performed on these words. Together with the results of our control task showing that participants could not identify masked words, it is therefore unlikely that conscious strategic processes such as stimulus-response mappings have been applied to masked action words and have subsequently affected preparation of the grasping movement. The issue of the depth of semantic processing of subliminal primes will certainly deserve extended research in the future. Future studies could for instance directly investigate whether subliminal action words displayed prior to movement preparation facilitates subsequent motor performance. One could also examine using fMRI whether subliminal action verbs activate the motor system and whether masked semantic priming for action words elicits the wellknown phenomenon of repetition suppression in brain motor regions.

Impairment of Action Verb Processing in Parkinson's Disease

So far, our studies together with previous works on action words have revealed that activations of brain regions that underlie motor performance are evident during processing of action verbs. However, whether these motor circuits are crucial for word retrieval or whether their activation is simply epiphenomenal was still undecided. Previous neuropsychological studies have reported deficits in the processing of action words and action concepts in braindamaged patients (Bak, O’Donovan, Xuereb, Boniface, \& Hodges, 2001; Neininger \& 
Pulvermüller, 2001, 2003; Tranel, Manzel, Asp, \& Kemmerer, 2008). For instance, Bak et al. (2001) reported selective deficit of verb processing in several members of a family affected by motor neuron disease. We aimed at corroborating these findings by investigating whether a motor pathology such as Parkinson's Disease (PD) affects action verb processing (Boulenger et al., 2008b). PD is a neurodegenerative disease caused by a dopaminergic deficiency of the nigrostriatal pathway, which mainly alters motor skills (akinesia/bradykinesia, tremor and muscle rigidity), although deficits in high-level cognitive functions such as memory have been described (Pillon, Boller, Levy, \& Dubois, 2001 for a review). Levodopa, or L-Dopa, which is transformed into dopamine, remains the standard for treating PD, providing relief from the symptoms and significantly improving quality of life. We hypothesized that if brain motor circuits contribute to action word understanding, PD patients off dopaminergic treatment should show a selective deficit in recognizing these words compared to words without specific motor associations. To avoid the use of mental imagery or controlled/strategic processes and instead favour automatic/implicit processes in word recognition, we used a classical masked repetition priming procedure with short SOA (stimulus onset asynchrony) between prime and target, forward and backward masks surrounding the prime and a task that encouraged speeded responses (Forster \& Davis, 1984). An upper-case prime-stimulus (action verb, non-action-related noun or meaningless consonant string), presented briefly (50 ms) and in close proximity with visual masks, preceded a lower-case target-stimulus (verb, noun or pseudo-word) which could be either identical to (repeated condition) or different from the prime (non-repeated condition). Participants had to perform a lexical decision task on targets by pressing one of two buttons as fast and accurately as possible. Ten non-demented PD patients and 10 healthy control subjects participated in the study. Patients fulfilled the UK Parkinson's Disease Brain Bank criteria for idiopathic PD (Gibb \& Lees, 1988). They showed good responsiveness to L-Dopa therapy and 
had been diagnosed between 1 and 17 years prior to their participation in the study. They performed the experiment twice in the same day: once off medication for at least $12 \mathrm{~h}(\mathrm{OFF}-$ phase) and once 60 min after intake of a supraliminar dose of Levodopa. After the experiment, none of the participants reported to have detected or identified the primes.

Analysis of response times (RTs) to words revealed that, as expected, healthy controls responded faster to words (both action verbs and concrete nouns) when they were preceded by an identical prime than by a consonant string. Net priming effects (i.e. difference in RTs between the non-repeated condition and the repeated condition) were similar for action verbs (40 ms) and concrete nouns (51 ms). Crucially, in PD patients in OFF, priming effects for concrete nouns $(81 \mathrm{~ms})$ were comparable to those observed in controls, whereas no significant priming was observed for action verbs (6 ms; Figure 3). In other words, RTs to action verbs in patients off treatment were not modulated by the nature of the prime as was observed for nonaction-related nouns. After Levodopa intake (ON), contrary to what was observed in the same patients in OFF, priming effects for action verbs restored (44 ms) and were strikingly comparable to those found for concrete nouns $(46 \mathrm{~ms})$ and in controls.

\section{Figure 3}

These findings therefore show that processing of action-related verbs can be selectively and subtly disrupted in a pathology that affects the motor system such as Parkinson's Disease. Masked priming effects are thought to reflect automatic and rapid access to lexico-semantic information about words and are usually explained in the context of spreading-activation theories (Collins \& Loftus, 1975; Davis, 2003). These theories assume that processing of the prime, even when it is not consciously perceived, increases its resting activation level in the lexico-semantic network and that this activation spreads automatically to related words, thus 
facilitating their later retrieval. In other words, as related pathways have been preactivated in the mental lexicon, targets that are identical to or share linguistic information with the prime can be processed more rapidly and accurately than different or unrelated targets. Note that this view has recently been challenged by studies suggesting that masked repetition priming does not reflect lexical processing but rather that it depends on stimulus-response mapping, i.e. the nature of the decision required by the task (Kinoshita \& Norris, 2010; Norris \& Kinoshita, 2008). In our study however, participants did not realize that a prime preceded the target, making it rather unlikely that they consciously took advantage of the response predicted by the prime to make a decision about the target. Electrophysiological studies have further brought compelling evidence that identity priming involves lexical access to prime and target (Holcomb et al., 2005; Holcomb \& Grainger, 2006; Monahan et al., 2008). In an MEG study, Monahan et al. (2008) for instance showed shorter latency of an early component (M250) peaking over temporal sites for targets preceded by masked identical primes than by control primes. The earliness of this effect together with its spatial topography corroborate the view that masked identity priming involves lexico-semantic processing rather than conscious decision processes which may occur later and involve more anterior regions such as the (pre)frontal cortex.

In our study, when PD patients were off medication, i.e., when motor dysfunction was strongest, no priming emerged for action verbs whereas robust priming effects were seen for concrete nouns. This suggests that under hypo-activation of the basal ganglia and of premotor and motor regions due to dopamine deficiency, lexico-semantic information about action verb primes could not be properly accessed and could thus not speed up identification of action verb targets. Levodopa intake, which increases dopamine levels in the striatum, then not only restored the function of premotor and motor regions via the fronto-striatal loop but also priming effects for action verbs. Our results thus mirror neuroimaging findings that show 
under-activation of motor/premotor regions, for instance in the form of reduced amplitude of the Readiness Potential, during movement preparation and execution in PD patients off treatment (Haslinger, Erhard, Kampfe, Boecker, Rummeny, Schwaiger, et al., 2001; Jahanshahi, Jenkins, Brown, Marsden, Passingham, \& Brooks, 1995). Following L-Dopa ingestion, motor impairment however improves, just as priming effects for action verbs restore. Our findings can be taken as evidence that brain signatures of action word meaning involve, beyond language areas, motor circuits and that processing of these words partly depend on the integrity of the motor system. It is noteworthy that motor regions do not seem to be necessary for action word processing as patients were able to correctly identify verbs, as attested by comparable RTs to verbs and nouns. The deficit in verb processing was only obvious when priming effects were measured, suggesting that redundancy in the languageaction network could compensate for the motor deficit and that other parts of the neural network underlying action verb processing were sufficient to identify these words. Such an assumption is in line with the multimodality hypothesis (Barsalou, 2008) which views representations of word meanings as including experiential traces from several modalities (sensory, motor, emotional etc.) that are reactivated during word processing (see also Taylor \& Zwaan, 2009). This would explain why damage to one modality, that is, incapacity of one modality to contribute to word representation, results in suboptimal, impoverished, but not abolished performance for word comprehension. Critical to future studies will be to investigate how the different modality-specific systems communicate in the dynamic process of word and concept understanding.

Altogether our study therefore suggests that the motor system contributes to action word retrieval, despite not being essential. As Parkinson's Disease affects the nigrostriatal pathway, our results, which document a "nigrostriatal modulation" of action verb processing, would benefit from other studies on patients with cortical motor lesions that would allow more 
directly specifying the role of the motor cortex in word recognition. Particularly, as already emphasized by Kemmerer and Gonzalez-Castillo (2010), there is need for future neuropsychological studies to investigate the impact of focal lesions to arm-, leg- and mouthrelated motor regions on the processing of verbs denoting actions performed with those same effectors. Our results further open perspectives for rehabilitation therapies in patients with brain lesions or motor diseases. Considering the tight and bidirectional functional links between language and action systems, previous studies have demonstrated the usefulness and relevance of language-action therapy in aphasic patients (see Pulvermüller \& Berthier, 2008 for a review). These studies indeed showed improvement of language performance in such patients after intensive therapy emphasizing language use in action context. In a similar vein, motor deficits of the upper limb after stroke has been shown to reduce after training based on action observation (Ertelt, Small, Solodkin, Dettmers, McNamara, Binkofski, \& Buccino, 2007; Franceschini, Agosti, Cantagallo, Salle, Mancuso, \& Buccino, 2010). From this, one could therefore imagine using action words as a tool to rehabilitate motor impairments in patients affected by motor/premotor cortical lesions or motor degenerative diseases. Following the reasoning of Pulvermüller and Berthier (2008), specific activation elicited by action words could "flow" from the language system to the motor system, potentially improving motor symptoms.

\section{Semantic Motor Somatotopy to Action-related Idioms}

Previous research that investigated the functional links between language and action has suffered from a major limitation: only concrete meaning of words and sentences has been examined (Boulenger et al., 2006; Buccino et al., 2005; Hauk et al., 2004; Tettamanti et al., 2005). Theories of embodied semantics however suggest that the use of figurative language 
also relies on embodied experience (Gibbs, 2003; Lakoff \& Johnson, 1999). A large body of work seems to corroborate this assumption (Gibbs, 1992; Gibbs, Bogdonvich, Sykes, \& Barr, 1997; Lakoff, 1987). For instance, Gibbs et al. (1997) showed faster lexical decision to words (e.g., heat) preceded by a related idiom (e.g., He blew his stack) than by an unrelated sentence (e.g., He saw many dents), suggesting that people compute or access embodied representations during idiom understanding. Accordingly, we sought to expand our previous findings by uncovering whether the motor system also comes into play during processing of idiomatic sentences that include action words (Boulenger et al., 2009). In an fMRI study, we identified brain signatures to silent reading of English idioms including arm- (e.g., He grasped the idea) or leg-related action verbs (e.g., He kicked the habit). We compared these activation patterns to those observed to sentences including the same action verbs but having a literal meaning (e.g., He grasped the object and He kicked the ball respectively). We examined fMRI activations in motor and premotor regions dedicated to arm and leg movements that were precisely localized using a motor task in which participants had to perform small movements of fingers and feet.

Our results revealed that reading of arm- and leg-related idiomatic and literal sentences specifically activated the motor/premotor cortex. Whereas sentences including arm action words elicited stronger activity in the left finger area, activity for leg sentences specifically spread to the left leg area in dorsocentral cortex (Figure 4). Hence, processing of actionrelated sentences, even with a figurative meaning, elicited somatotopic activation of the motor cortex that overlapped with that observed during actual movement execution. A similar pattern of results emerged in an additional analysis carried out in several regions along the motor strip extending from dorsal to more lateral areas (for more details see Boulenger et al., 2009). Importantly, although idioms activated left perisylvian fronto-temporal areas more strongly than literal sentences, both types of sentences activated motor regions equally. One 
could argue that semantic somatotopy in lateral/dorsal frontocentral regions for arm/legrelated sentences, respectively, was due to processing of action verbs per se. However, motor activation was relatively weak at action word onset (on average $1.2 \mathrm{~s}$ before critical word onset) and at presentation of critical words. It rather became particularly evident when the modeled haemodynamic response was time-locked to a point delayed by $3 \mathrm{~s}$ after the critical words, suggesting that semantic motor somatotopy reflected processing of sentence-level meaning (Humphries, Binder, Medler, \& Liebenthal, 2007; Pulvermüller, 2007). We suggested that the computation of abstract meaning in the brain not only involves languagerelated regions in fronto-temporal cortex but also distributed networks in the sensory-motor system that may come into play rather late in the construction of sentence meaning. A recent fMRI study corroborates our findings as activation of motion-sensitive visual areas (MT) was shown during processing of sentences depicting fictive motion situations (Saygin, McCullough, Alac, \& Emmorey, 2009; see also Glenberg, Sato, Cattaneo, Riggio, Palumbo, \& Buccino, 2008 and Glenberg \& Kaschak, 2002 for similar results). Other studies however did not find any specific motor activation for processing abstract/figurative language related to action words (Aziz-Zadeh, Wilson, Rizzolatti, \& Iacoboni, 2006; Raposo, Moss, Stamatakis, \& Tyler, 2009; Ruschemeyer, Brass, \& Friederici, 2007). Ruschemeyer et al. (2007) for instance demonstrated activity in motor regions for reading simple action verbs (e.g., greifen/'to grab') compared to abstract verbs but not for complex morphological verbs built on motor stems (e.g., begreifen/'to comprehend'). The authors proposed that the overall meaning of morphologically complex words prevails over meanings of their morphological components during word processing. Aziz-Zadeh et al. (2006) also failed to find motor activation for metaphorical sentences including action verbs. However, several methodological issues (e.g., each sentence was repeated 8 times) in this study may have prevented motor activity to come out. Hence there are still inconsistencies in the literature as 
to the involvement of motor cortex in figurative language processing, leaving open issues and perspectives for future studies in the field. Future works using neurophysiological techniques such as EEG or MEG (MagnetoEncephaloGraphy) that allow tracking brain activations in the millisecond range are also required to decide exactly when motor centres are recruited during idiom comprehension.

Figure 4

Our findings also allowed addressing the more general issue of figurative language understanding which we commonly use to express our ideas and thoughts. Two main theories have been offered to account for idiom comprehension. In the "configurational hypothesis", Cacciari and Tabossi (1988) proposed that idiom meaning is computed from the meanings of individual words of the sentence and from combinatorial information. Idioms would be processed literally until a word, the "idiomatic key", is encountered that prompts recognition of the idiomatic nature of the sentence and thus guide the idiomatic interpretation. By contrast, the "lexical representation hypothesis" (Swinney \& Cutler, 1979) assumes that idioms are stored separate from their constituents as whole lexical items and that they are retrieved in memory and processed similarly as long words are. The semantic somatotopy we observed to action-related idioms supports the configurational hypothesis (Cacciari \& Tabossi, 1988) by suggesting that meaning aspects of words that compose the sentences are accessed and combined when general sentence meaning is computed. These motor schemata reflecting concrete referential aspects of words would contribute to the comprehension process yielding idiom meaning. It is still possible however that computation of the compositional meaning that involves the sensory-motor system occurs in parallel with access to idioms as abstract patterns that may involve fronto-temporal language areas. Future work 
investigating the time-course of brain activations during idiom comprehension should be able to distinguish between the configurational and the lexical hypotheses of idiom processing or to provide evidence that the two are not entirely incompatible.

\section{General Discussion}

Our findings together with previous research on embodied language suggest that the online processing of action verb meaning involves or interacts with the same processes and structures that generate bodily actions. This cross-talk occurs not only for literal language processing but also for figurative language as reading of action words embedded in idiomatic sentences also shows signature effects of the motor system. They further suggest that motor circuits are not activated epiphenomenally during language comprehension but that they contribute to access to lexico-semantic information about words. In other words, motor activation during action word processing would be part of word decoding. Our results therefore support the view that word meaning, be it concrete or abstract, is understood in reference to grounded physical meanings (Barsalou, 2008; Pulvermüller, 2005).

Two interpretations can account for the functional links between language and action. First, action word recognition could lead to automatic simulation of the actions depicted by the words that would occur at a post-lexical stage of processing. Such motor simulation would provide access to the "pragmatic meaning" of words, namely the description that the words give to the actions (Jeannerod, 2006), which is distinct from word semantic analysis. This view that language understanding relies on mental simulation is best explained in the framework of the mirror system theory which postulates that actions are understood through the mapping of perceived actions of others to one's own motor repertoire (Rizolatti \& Craighero, 2004). Mirror neurons, initially discovered in the monkey ventral premotor cortex, 
discharge not only during execution of grasping movements but also during observation of the same actions performed by another monkey or the experimenter. Mirror neurons have been found to respond to hand and mouth actions and even to the sounds evoked by actions (i.e. “echo neurons"; for a review, see Rizolatti \& Craighero, 2004). In humans, neuroimaging studies have revealed the existence of a similar mirror mechanism as observation of others' actions recruits the same fronto-parietal network that is activated during movement execution (Buccino, Binkofski, Fink, Fadiga, Fogassi, Gallese, et al., 2001). As to language understanding, the mirror system theory suggests that retrieving action word meaning creates a motor resonance in the brain's motor/premotor regions, just as action observation does (Tettamanti et al., 2005). "Comprehending the linguistic description of an action might involve covertly recapitulating the type of action that it refers to, using some of the same brain systems that underlie execution and observation of that type of action" (Kemmerer \& Gonzalez-Castillo, 2010). This interpretation in terms of simulation processes, despite being appealing, however does not account for the earliness of language-induced motor effects (within 150-200 ms of action word onset). A different interpretation assumes that wordrelated motor activation occurs because of the links between an action and its verbal description that are actively formed during the language learning period (Pulvermüller, 2001, 2005). Through Hebbian correlation learning, whenever an action word is encountered during language acquisition (e.g., hearing kick the ball while playing football, which links the word kick with the action of kicking), the motor program and the neural representation of the word become active simultaneously so that cortical connections between motor and language areas strengthen. The brain's systems for action and language would thus develop tight functional connections that allow for rapid processing of multimodal information across distributed cortical networks (Pulvermüller, 2005). Studies on word learning in children seem to support this view. As caretakers typically produce an action verb to prompt children to perform the 
corresponding action (Goldfield, 2000), early-learned verbs often refer to very specific bodily actions (Maouene, Hidaka, \& Smith, 2008). There is also evidence that children learn verb meaning better by performing the actions themselves than by observing others' actions (Huttenlocher, Smiley, \& Chaney, 1983). Using fMRI, James and Maouene (2009) demonstrated that in 5-year old children, auditory perception of hand- and leg-related action verbs elicited somatotopic activation of motor regions involved in action execution. Altogether these data agree with our assumption that learning age of action verbs partly depend on the age at which children are able to perform the described actions (Boulenger et al., 2007). They also suggest that the functional links between language and action are early and strong and that they should persist in adults. Motor regions, which probably involve mirror neurons, could thus be an intrinsic part of the cortical network underlying processing of word meaning in children and adults. The issue of the exact function of language-induced motor activity however warrants further investigation. Although motor activity during action word processing is strong enough to interfere with motor behaviour (Boulenger et al., 2006, 2008a), the motor contribution appears rather subtle as word processing is compromised but still possible when the motor system itself is damaged (Boulenger et al., 2008b). So far, the existing data thus provide evidence that motor regions constitute a substantial part of semantic representations of action words, but they do not allow asserting that motor regions are essential for action word understanding (Mahon \& Caramazza, 2005, 2008). One possibility is that motor regions play a crucial role in action word comprehension in children in the dynamics of language acquisition (Maouene et al., 2008) and that in adults, only residuals of this activity are observed. Alternatively, semantic representations could be stored in multimodal functional networks carrying sensory, motor and more abstract information (Barsalou, 2008) so that the contribution of motor regions would not be an all-or-none phenomenon (i.e. motor activation during action word comprehension would be labile 
depending on context and participants) and motor dysfunction would lead to suboptimal performance for word processing (Taylor \& Zwaan, 2009). Future studies in brain-lesioned patients and using brain imaging techniques are required to better capture how the language/motor architecture develops. For instance, one could examine action verb processing in children at different ages, i.e. with different exposure to language. Studies in adults who learn new "verbs" (i.e. pseudo-verbs) associated with novel bodily actions would also inform us about how and when motor regions come to contribute to language understanding. 


\section{References}

Abrams, R. L., and Greenwald, A. G. 2000 Parts outweigh the whole (word) in unconscious analysis of meaning. Psychological Science, 11, 118-124.

Aziz-Zadeh, L., Wilson, S. M., Rizzolatti, G., and Iacoboni, M. (2006). Congruent embodied representations for visually presented actions and linguistic phrases describing actions. Current Biology, 16(18), 1818-1823.

Bak, T. H., O’Donovan, D. G., Xuereb, J. H., Boniface, S., and Hodges, J. R. (2001). Selective impairment of verb processing associated with pathological changes in Brodmann areas. Brain, 124(1), 103-120.

Barsalou, L. W. (2008). Grounded cognition. Annual Review Psychology, 59, 617-645.

Boulenger, V., Hauk, O., and Pulvermüller, F. (2009). Grasping ideas with the motor system: semantic somatotopy in idiom comprehension. Cerebral Cortex, 19(8), 1905-1914.

Boulenger, V., Mechtouff, L., Thobois, S., Broussolle, E., Jeannerod, M., and Nazir, T. A. (2008b). Word processing in Parkinson's disease is impaired for action verbs but not for concrete nouns. Neuropsychologia, 46(2), 743-756.

Boulenger, V., Silber, B. Y., Roy, A. C., Paulignan, Y., Jeannerod, M., and Nazir, T. A. (2008a). Subliminal display of action words interferes with motor planning: a combined EEG and kinematic study. Journal of Physiology Paris, 102(1-3), 130-136.

Boulenger, V., Decoppet, N., Roy, A. C., Paulignan, Y., and Nazir, T. A. (2007). Differential effects of age-of-acquisition for concrete nouns and action verbs: Evidence for partly distinct representations? Cognition, 103, 131-146.

Boulenger, V., Roy, A. C., Paulignan, Y., Deprez, V., Jeannerod, M., and Nazir, T. A. (2006). Cross-talk between language processes and overt motor behavior in the first $200 \mathrm{~ms}$ of processing. Journal of Cognitive Neuroscience, 18(10), 1607-1615. 
Buccino, G., Riggio, L., Melli, G., Binkofski, F., Gallese, V., and Rizzolatti, G. (2005). Listening to action-related sentences modulates the activity of the motor system: A combined TMS and behavioral study. Cognitive Brain Research, 24, 355-363.

Buccino, G., Binkofski, G., Fink, G. R., Fadiga, L., Fogassi, L., Gallese, V., Seitza, R. J., Zilles, G., Rizzolatti, G., and Freund, H. J. (2001). Action observation activates the premotor and parietal areas in a somatotopic manner: an fMRI study. European Journal of Neuroscience, 13, 400-404.

Bueno, S. and Frenck-Mestre, C. (2008). The activation of semantic memory: effects of prime exposure, prime-target relationship and task demands. Memory and Cognition, 36(4), 882_898.

Cacciari, C., and Tabossi, P. (1988). The comprehension of idioms. Journal of Memory and Language, 27, 668-683.

Caramazza, A., and Hillis, A. E. (1991). Lexical organization of nouns and verbs in the brain. Nature, 349, 788-790.

Carroll, J. B., and White, M. N. (1973). Age of acquisition norms for 220 picturable nouns. Journal of Verbal Learning and Verbal Behavior, 12, 563-576.

Colebatch, J. G. (2007). Bereitschafts potential and movement-related potentials: origin, significance, and application in disorders of human movement. Movement Disorders 22(5), 601-610.

Collins, A. M., and Loftus, E. F. A. (1975). A spreading-activation theory of semantic processing. Psychological Review, 82, 407-428.

Damasio, A. R., and Tranel, D. (1993). Nouns and verbs are retrieved with differently neural systems. Proceedings of the National Academy of Science, 90, 4957-4960.

Damian, M. F. (2001). Congruity effects evoked by subliminally presented primes: 
automaticity rather than semantic processing. Journal of Experimental Psychology: Human Perception and Performance, 27(1), 154-165.

Davis, C. J. (2003). Factors underlying masked priming effects in competitive network models of visual word recognition. In S. Kinoshita \& S. J. Lupker (Eds.), Masked priming: The state of the art (pp. 121-170). New York: Psychology Press.

Dehaene, S., Naccache, L., Cohen, L., Le Bihan, D., Mangin, J.F., Poline, J.B., and Rivière, D. (2001). Cerebral mechanisms of word masking and unconscious repetition priming. Nature Neuroscience, 4(7), 752-758.

Dehaene, S., Naccache, L., Le Clec'H, G., Koechlin, E., Mueller, M., Dehaene-Lambertz, G., van de Moortele, P.F., and Le Bihan, D. (1998). Imaging unconscious semantic priming. Nature, 395, 597-600.

Desai, R. H., Binder, J. R., Conant, L. L., and Seidenberg, M. S. (2010). Activation of sensory-motor areas in sentence comprehension. Cerebral Cortex, 20(2), 468-478.

Diaz, M.T., and McCarthy G. (2007). Unconscious word processing engages a distributed network of brain regions. Journal of Cognitive Neuroscience, 19(11), 1768-1775.

Ertelt, D., Small, S., Solodkin, A., Dettmers, C., McNamara, A., Binkofski, F., and Buccino, G. (2007). Action observation has a positive impact on rehabilitation of motor deficits after stroke. Neuroimage, 36(suppl 2), 164-173.

Fischer, M. H., and Zwaan, R. A. (2008). Embodied language: A review of the role of the motor system in languagecomprehension. Quarterly Journal of Experimental Psychology, $61(6), 825-850$

Forster, K. I., and Davis, C. (1984). Repetition priming and frequency attenuation in lexical access. Journal of Experimental Psychology: Learning, Memory, and Cognition, 10, 680698. 
Franceschini, M., Agosti, M., Cantagallo, A., Salle, P., Mancuso, M., and Buccino, G. (2010). Mirror neurons: Action observation treatment as a tool in stroke rehabilitation. European Journal of Physical and Rehabilitation Medicine.

Gainotti, G., and Silveri, M. (1996). Cognitive and anatomical locus of lesion in a patient with a category-specific impairment for living beings. Cognitive Neuropsychology, 13, 357-389.

Gallese, V., and Lakoff, G. (2005). The brain's concepts: The role of the sensory-motor system in conceptual knowledge. Cognitive Neuropsychology, 22, 455-479.

Ghyselinck, M., Lewis, M. B., and Brysbaert, M. (2004). Age of acquisition and the cumulative frequency hypothesis: a review of the literature and a new multi-task investigation. Acta Psychologica., 115(1), 43-67.

Gibbs, R. W. (2003). Embodied experience and linguistic meaning. Brain and Language, 84, $1-15$.

Gibbs, R. (1992). Why idioms mean what they do? Journal of Memory and Language, 31, 485-506.

Gibbs, R., Bogdonvich, J., Sykes, J., and Barr, D. (1997). Metaphor in idiom comprehension. Journal of Memory and Language, 37, 141-154.

Gibb, W. R., and Lees, A. J. (1988). The relevance of the Lewy body to the pathogenesis of idiopathic Parkinson's disease. Journal of Neurology Neurosurgery and Psychiatry, 51, 745-752.

Glenberg, A. M., Sato, M., Cattaneo, L., Riggio, L., Palumbo, D., \& Buccino, G. (2008). Processing abstract language modulates motor system activity. Quarterly Journal of Experimental Psychology, 61(6), 905-919.

Glenberg, A. M., and Kaschak, M. P. (2002). Grounding language in action. Psychonomic Bulletin and Review, 9(3), 558-565.

Gold, B.T., Balota, D.A., Jones, S.J., Powell, D.K., Smith, C.D., and Andersen, A.H. (2006). 
Dissociation of automatic and strategic lexical-semantics: functional magnetic resonance imaging evidence for differing roles of multiple frontotemporal regions. Journal of Neuroscience, 26, 6523-6532.

Goldberg, R. F., Perfetti, C. A., and Schneider, W. (2006). Perceptual knowledge retrieval activates sensory brain regions. Journal of Neuroscience, 26(18), 4917-4921.

Goldfield, B. A. (2000). Nouns before verbs in comprehension vs. production: the view from pragmatics. Journal of Child Language, 27(3), 501-520.

Greenwald, A.G., Draine, S.C., and Abrams, R.L. (1996). Three cognitive markers of unconscious semantic activation. Science, 273, 1699-1702.

Haslinger, B., Erhard, P., Kampfe, N., Boecker, H., Rummeny, E., Schwaiger, M., Conrad, B., and Ceballos-Baumann, A. O. (2001). Event-related functional magnetic resonance imaging in Parkinson's disease before and after levodopa. Brain, 124(3), 558-570.

Hauk, O., Pulvermüller, F., Ford, M., Marslen-Wilson, W., and Davis, M. H. (2009). Can I have a quick word? Early electrophysiological manifestations of psycholinguistic processes revealed by event-related regression analysis of the EEG. Biological Psychiatry, 80(1), 64-74.

Hauk, O., Davis, M.H., Kherif, F., and Pulvermüller, F. (2008). Imagery or meaning? Evidence for a semantic origin of category-specific brain activity in metabolic imaging. European Journal of Neuroscience, 27(7), 1856-1866.

Hauk, O., Johnsrude, I., and Pulvermuüller, F. (2004). Somatotopic representation of action words in human motor and premotor cortex. Neuron, 41, 301-307.

Hauk, O., and Pulvermüller, F. (2004). Neurophysiological distinction of action words in the fronto-central cortex. Human Brain Mapping, 21(3), 191-201.

Holcomb, P. J., and Grainger, J. (2006). On the time course of visual word recognition: An 
event-related potential investigation using masked repetition priming. Journal of Cognitive Neuroscience, 18, 1631-1643.

Holcomb, P. J., Reder, L., Misra, M., and Grainger, J. (2005). Masked priming: An eventrelated brain potential study of repetition and semantic effects. Brain Research, Cognitive Brain Research, 24, 155-172.

Holt, L. E., and Beilock, S. S. (2006). Expertise and its embodiment: examining the impact of sensorimotor skill expertise on the representation of action-related text. Psychonomic Bulletin Review, 13(4), 691-701.

Humphries, C., Binder, J. R., Medler, D. A., and Liebenthal, E. (2007). Time-course of semantic processes during sentence comprehension: an fMRI study. Neuroimage, 36, 924932.

Huttenlocher, J., Smiley, P., and Chaney, R. (1983). Emergence of action categories in the child: Evidence from verb meanings. Psychological Review, 90, 72-93.

Jahanshahi, M., Jenkins, I. H., Brown, R. G., Marsden, C. D., Passingham, R. E., and Brooks, D. J. (1995). Self-initiated versus externally triggered movements. I. An investigation using measurement of regional cerebral blood flow with PET and movement-related potentials in normal and Parkinson's disease subjects. Brain, 119(3), 1045-1048.

James, K. H., and Maouene, J. (2009). Auditory verb perception recruits motor systems in the developing brain: an fMRI investigation. Developmental Science, 12(6), 26-34.

Jeannerod, M. (2006). Motor cognition: what action tells the self. New York: Oxford University Press.

Kemmerer, D., and Gonzalez-Castillo, J. (2010). The Two-Level Theory of verb meaning: An approach to integrating the semantics of action with the mirror neuron system. Brain and Language, 112, 54-76.

Kiefer, M. (2002). The N400 is modulated by unconsciously perceived masked words: further 
evidence for a spreading activation account of N400 priming effects. Cognitive Brain Research, 13, 27-39.

Kinoshita, S. and Norris, D. (2010). Masked priming effect reflects evidence accumulated by the prime. Quarterly Journal of Experimental Psychology, 63, 194-204.

Kornhuber, H. H., and Deecke, L. (1965). Changes in the brain potential in voluntary movements and passive movements in man: readiness potential and reafferent potential. Pflugers Arch Gesamte Physiol Menschen Tiere, 284, 1-17.

Kouider, S., and Dehaene, S. (2007). Levels of processing during non-conscious perception: a critical review of visual masking. Philosophical Transactions of the Royal Society of London, Series B, Biological Sciences, 362, 857-875.

Lakoff, G. (1987). Women, fire, and dangerous things. Chicago: University of Chicago Press.

Lakoff, G., and Johnson, M. (1999). Philosophy in the flesh: the Embodied mind and its challenge to western thought. New York: Basic Books.

Mahon, B. Z., and Caramazza, A. (2008). A critical look at the embodied cognition hypothesis and a new proposal for grounding conceptual content. Journal of Physiology Paris, 102, 59-70.

Mahon, B. Z., and Caramazza, A. (2005). The orchestration of the sensory-motor systems: Clues from neuropsychology. Cognitive Neuropsychology, 22, 480-494.

Maouene, J., Hikada, S., and Smith, L. B. (2008). Body parts and early-learned verbs. Cognitive Science, 32(7), 1200-1216.

Marcel, A. J. (1983). Conscious and unconscious perception: Experiments on visual masking and recognition. Cognitive Psychology, 15, 197-237.

Martin, A. (2007). The representation of object concepts in the brain. Annual Review of Psychology, 58, 25-45. 
Martin, A., Chao, L. L. (2001). Semantic memory and the brain: structure and processes. Current Opinion in Neurobiology, 11(2), 194-201.

Martin, A., Wiggs, C. L., Ungerleider, L. G, and Haxby, J. V. (1996). Neural correlates of category-specific knowledge. Nature, 379, 649-652.

Monahan, P.J., Fiorentino, R., and Poeppel, D. (2008). Masked repetition priming using magnetoencephalography. Brain and Language, 106(1), 65-71.

Naccache, L., Gaillard, R., Adam, C., Hasboun, D., Clemenceau, S., Baulac, M., Dehaene, S., and Cohen, L. (2005). A direct intracranial record of emotions evoked by subliminal words. Proceedings of the National Academy of Sciences, USA, 102 (21), 7713-7717.

Nazir, T. A., Boulenger, V., Roy, A. C., Silber, B., Jeannerod, M., and Paulignan, Y. (2008). Language-induced motor perturbations during the execution of a reaching movement. Quarterly Journal of Experimental Psychology, 61(6), 933-943.

Neely, J. H. (1991). Semantic priming effects in visual word recognition: A selective review of current findings and theories. In D. Besner \& G. Humphreys (Eds.), Basic processes in reading: Visual word recognition (pp.264-336). Hillsdale, NJ: Erlbaum.

Neininger, B. and Pulvermüller, F. (2003). Word-category specific deficits after lesions in the right hemisphere. Neuropsychologia, 41(1), 53-70.

Neininger, B. and Pulvermüller, F. (2001). The right hemisphere's role in action word processing: a double case study. Neurocase, 7(4), 303-317.

Norris, D., and Kinoshita, S. (2008). Perception as evidence accumulation and Bayesian inference: Insights from masked priming. Journal of Experimental Psychology: General, $137,433-455$.

Pascual-Leone, A., Tormos, J. M., Keenan, J., Tarazona, F., Canete, C., and Catala, M. D. (1998). Study and modulation of human cortical excitability with transcranial magnetic stimulation. Journal of Clinical Neurophysiology, 15(4), 333-343. 
Perea, M., and Gotor, A. (1997). Associative and semantic priming effects occur at very short stimulus-onset asynchronies in lexical decision and naming. Cognition, 62, 223-240.

Pillon, B., Boller, F., Levy, R., and Dubois, B. (2001). Cognitive deficits and dementia in Parkinson's disease. In F. Boller \& S. Cappa (Eds.), Aging and dementia (pp.311-371). Amsterdam: Elsevier Science B.V.

Posner, M. I., and Snyder, C. R. R. (1975). Facilitation and inhibition in the processing of signals, In P. M. A. Rabbitt \& S. Dornic (Eds.), Attention and Performance (pp.669-682). London: Academic Press.

Pulvermüller, F. (2007). Brain processes of word recognition as revealed by neurophysiological imaging. In G. Gaskell (Ed.), The Oxford Handbook of psycholinguistics (pp.119-139). Oxford: Oxford University Press.

Pulvermüller, F. (2005). Brain mechanisms linking language and action. Nature Reviews Neuroscience, 6, 576-582.

Pulvermüller, F. (2001). Brain reflections of words and their meaning. Trends in Cognitive Sciences, 5, 517-525.

Pulvermüller, F., and Fadiga, L. (2010). Active perception: sensorimotor circuits as a cortical basis for language. Nature Reviews Neuroscience, 11(5), 351-360.

Pulvermüller, F., and Berthier, M.L. (2008). Aphasia therapy on a neuroscience basis. Aphasiology, 22(6), 563-599.

Pulvermüller, F., Shtyrov, Y., and Ilmoniemi, R.J. (2005a). Brain signatures of meaning access in action word recognition. Journal of Cognitive Neuroscience, 17(6), 884-892.

Pulvermüller, F., Hauk, O., Nikulin, V. V., and Ilmoniemi, R. J. (2005b). Functional links between motor and language systems. European Journal of Neuroscience, 21(3), 793-797.

Quinn, and Kinoshita (2008). Category congruence effect in semantic categorization with 
masked primes with narrow and broad categories. Journal of Memory and Language, 58, 286-306.

Raposo, A., Moss, H. E., Stamatakis, E. A., and Tyler, L. K. (2009). Modulation of motor and premotor cortices by actions, action words and action sentences. Neuropsychologia, 47(2), 388-396.

Rastle, K. (2007). Visual word recognition. In G. Gaskell (Ed.), The Oxford Handbook of psycholinguistics (pp.71-87). Oxford: Oxford University Press.

Rizzolatti, G., and Craighero, L. (2004). The mirror neuron system. Annual Review of Neuroscience, 27, 169-192.

Rueschemeyer, S. A., Lindemann, O., van Rooij, D., van Dam, W., and Bekkering, H. (2010). Effects of intentional motor actions on embodied language processing. Experimental Psychology, 57(4), 260-266.

Rueschemeyer, S. A., Brass, M., and Friederici, A. D. (2007). Comprehending prehending: neural correlates of processing verbs with motor stems. Journal of Cognitive Neuroscience, $19(5), 855-865$.

Saygin, A. P., McCullough, S., Alac, M., and Emmorey, K. (2009). Modulation of BOLD response in motion-sensitive lateral temporal cortex by real and fictive motion sentences. Journal of Cognitive Neuroscience, PMID: 19925197.

Schmidt, R. A., Zelaznik, H. N., and Frank, J. S. (1979). Sources of inaccuracy in rapid movement. In G.E. Stelmach (Ed.), Information Processing in Motor Control and Learning (pp.183-203). New York: Academic Press.

Scorolli, C. and Borghi, A. M. (2007). Sentence comprehension and action: Effector specific modulation of the motor system. Brain Research, 1130, 119-124. 
Shtyrov, Y., Hauk, O., and Pulvermüller, F. (2004). Distributed neuronal networks for encoding category-specific semantic information: the mismatch negativity to action words. European Journal of Neuroscience, 19(4), 1083-1092.

Simmons, W. K., Martin, A., and Barsalou, L.W. (2005). Pictures of appetizing foods activate gustatory cortices for taste and reward. Cerebral Cortex, 15, 1602-1608.

Swinney, D. A., and Cutler, A. (1979). The access and processing of idiomatic expression. Journal of Verbal Learning and Verbal Behaviour, 18, 523-534.

Taylor, L. J., and Zwaan, R. A. (2009). Action in cognition: The case of language. Language and Cognition, 1(1), 45-58.

Tettamanti, M., Buccino, G., Saccuman, M. C., Gallese, V., Danna, M., Scifo, P., Fazio, F., Rizzolatti, G., Cappa, S. F., and Perani, D. (2005). Listening to action related sentences activates fronto-parietal motor circuits. Journal of Cognitive Neuroscience, 17, 273-281.

Thevenet, M., Paulignan, Y., \& Prablanc, C. (2001). OPTODISP Program. License INSERMCNRS-UCBL.

Tranel, D., Manzel, K., Asp, E., and Kemmerer, D. (2008). Naming dynamic and static actions: neuropsychological evidence. Journal of Physiology Paris, 102(1-3), 80-94.

Tucker, M., and Ellis, R. (2004). Action priming by briefly presented objects. Acta Psychologica, 116, 185-203.

Ullman, M. T. (2007). The biocognition of the mental lexicon. In G. Gaskell (Ed.), The Oxford Handbook of psycholinguistics (pp.267-286). Oxford: Oxford University Press.

Walsh, V., and Cowey, A. (2000). Transcranial magnetic stimulation and cognitive neuroscience. Nature Reviews Neuroscience, 1, 73-79.

Warrington, E. K. and Shallice, T. (1984). Category specific semantic impairments. Brain, 107(3), 829-854.

Wheatley, T., Weisberg, J., Beauchamp, M.S. \& Martin, A. (2005) Automatic priming of 
semantically related words reduces activity in the fusiform gyrus. Journal of Cognitive Neuroscience, 17, 1871-1885.

Zwaan, R. A., and Taylor, L. J. (2006). Seeing, acting, understanding: motor resonance in language understanding. Journal of Experimental Psychology General, 135(1), 1-11. 
Figure Captions

Figure 1. Latency of the wrist acceleration peak during reading of action verbs (grey) and concrete nouns (black) in Experiment 1 (simultaneous language and motor tasks) and Experiment 2 (language task before movement). (*) indicates a significant difference between conditions. The procedure of each experiment is illustrated by the schemas at the top (adapted from Boulenger et al., 2006).

Figure 2. Mean gradient of the Readiness Potential (RP) and mean amplitude of the wrist acceleration peak in the action verb (grey) and concrete noun (black) conditions. $\left(^{*}\right)$ indicates a significant difference between conditions (from Boulenger et al., 2008a).

Figure 3. Net repetition priming effects (i.e. difference in reaction times between the nonrepeated condition and the repeated condition) for action verbs (grey) and concrete nouns (black) in Parkinson's patients off dopaminergic treatment (OFF), after Levodopa intake (ON) and in healthy controls. $(*)$ indicates a significant difference between conditions (adapted from Boulenger et al., 2008b).

Figure 4. Semantic motor somatotopy to idioms and literal sentences that include arm- (red) and leg-related (blue) action words. Bar graphs represent mean parameter estimates for dorsal and lateral regions along the motor strip (the /x/ and /z/coordinates are reported). The locations of these regions are reported (yellow circles) on a coronal slice of the brain on which activations elicited by finger (red) and foot (blue) movements are displayed. Somatotopic activation to arm and leg sentences is also shown on a standard brain surface (bottom left corner; adapted from Boulenger et al., 2009). 
FIGURE 1
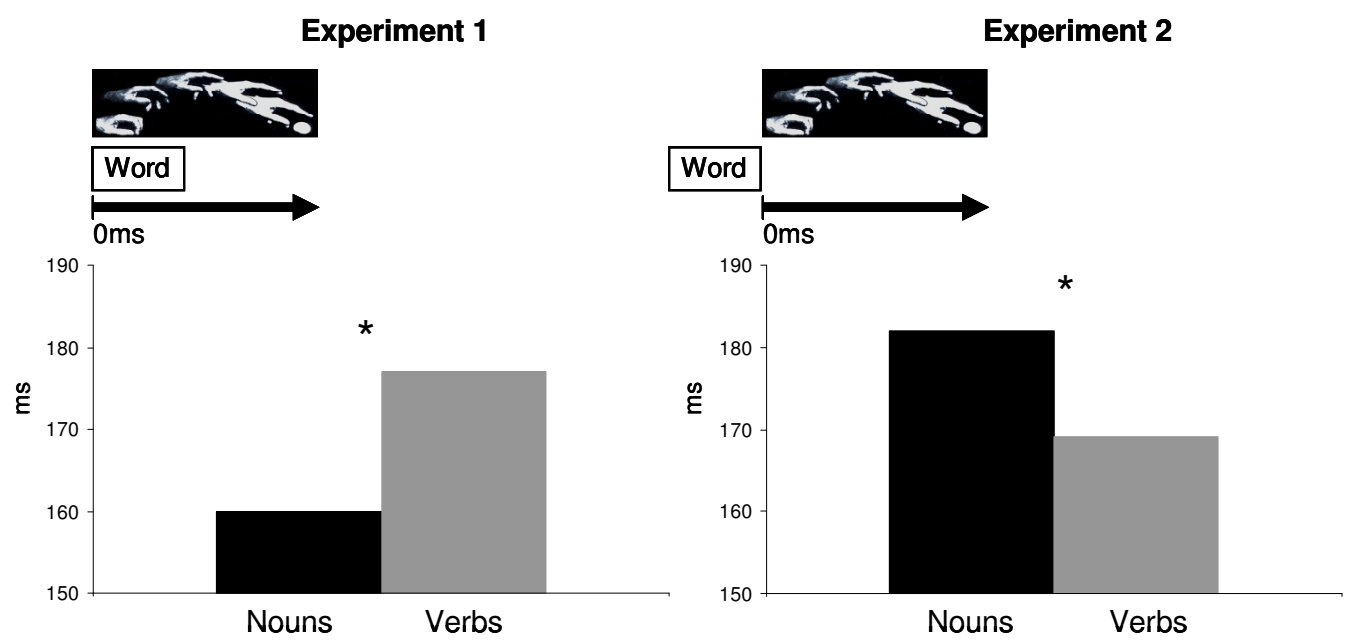
FIGURE 2
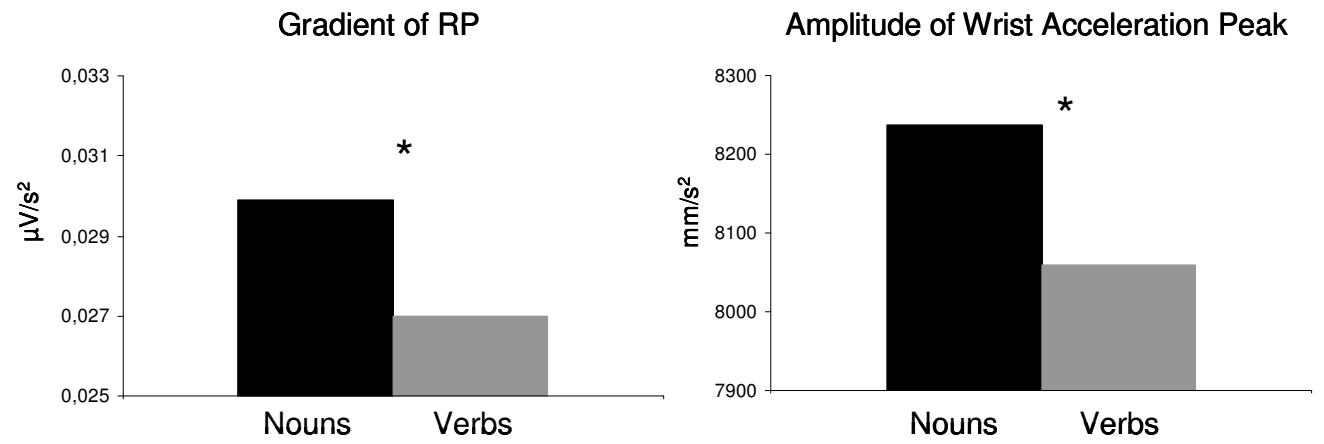
FIGURE 3

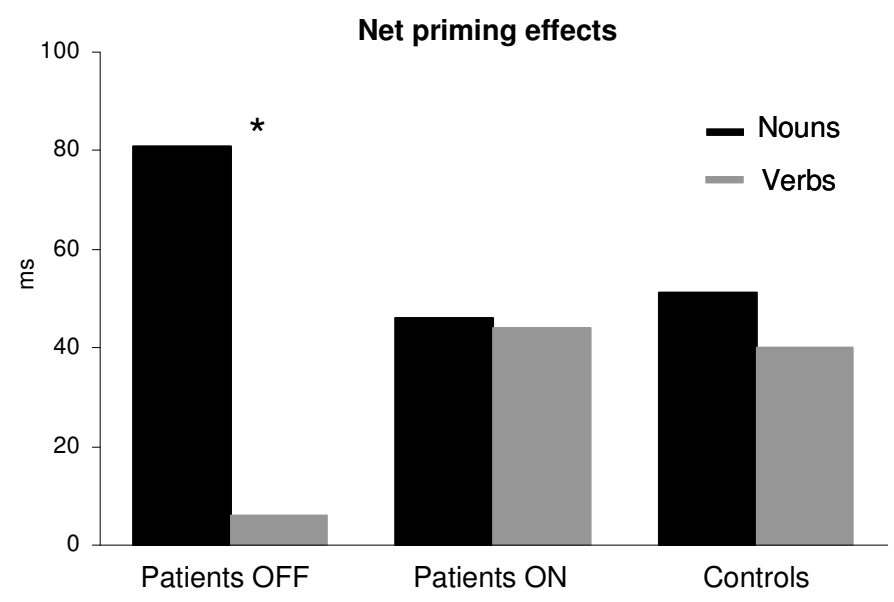


FIGURE 4

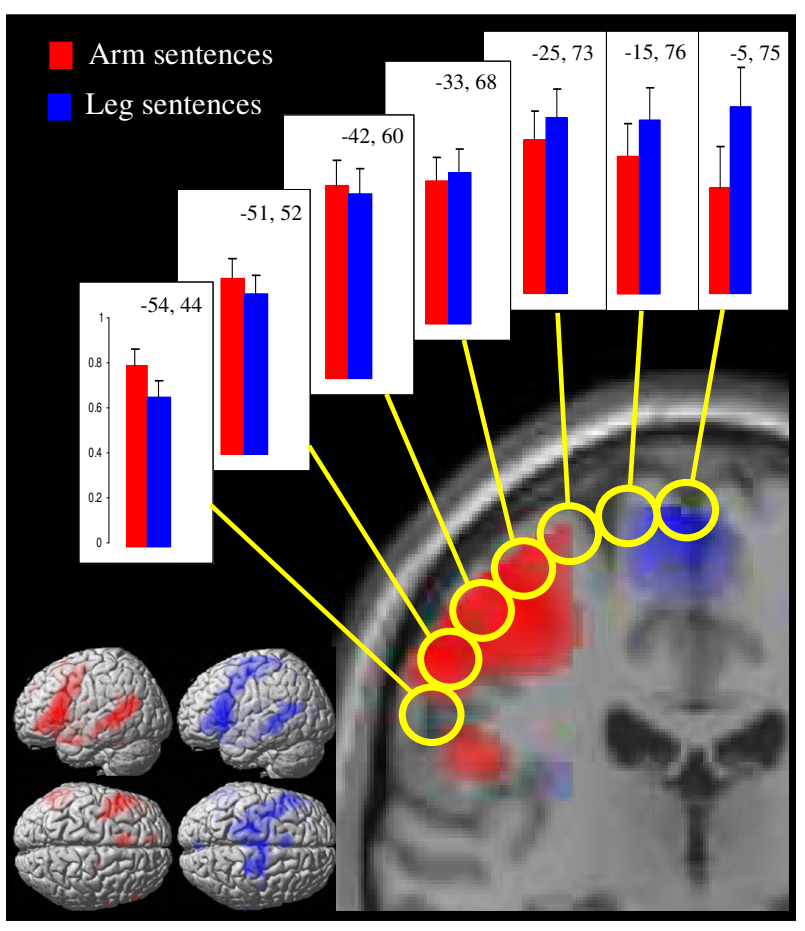

